\title{
Beyond Atherothrombotic Disease in Acute Coronary Syndrome
}

\author{
Mayra Alejandra Mora, ${ }^{1}$ Manuela Molano-Perez, ${ }^{\circledR}{ }^{\circledR}$ Cristian Orlando Becerra-Gonzalez, ${ }^{3}$ Kenny Buitrago- \\ Toro, ${ }^{1,3}$ Silvana Jimenez-Salazar, ${ }^{10}$ Carlos Ortiz ${ }^{(\bullet}$ \\ Universidad Surcolombiana Facultad de Salud, ${ }^{1}$ Neiva, Huila - Colômbia \\ Universidad del Rosario, ${ }^{2}$ Bogotá - Colômbia \\ Universidad Tecnologica de Pereira Facultad de Ciencias de la Salud, ${ }^{3}$ Pereira, Risaralda - Colômbia \\ Fundacion Cardioinfantil - Instituto de Cardiologia, ${ }^{4}$ Bogotá, Cundinamarca - Colômbia
}

\section{Abstract}

Half of the global population over 20 years of age will be affected by cardiovascular disease. Cardiovascular events in young people is challenging. Spontaneous coronary artery dissection is a non-traumatic and noniatrogenic separation of the coronary arterial wall and is an uncommon and underdiagnosed cause of acute myocardial infarction predominately found in young women. Medical management has been more widely accepted, with percutaneous and surgery treatment reserved for precise indications. Optimal control of individual risk factors is essential in order to avoid recurrences.

\section{Introduction}

Total cardiovascular disease (coronary heart disease, heart failure, cerebrovascular disease, and systemic arterial hypertension ) globally affects up to $48 \%$ of all adults over 20 years of age, a trend that is increasing in prevalence and mortality, especially in countries of low resources, characterized by a high prevalence of comorbidities. ${ }^{1}$

The incidence of acute myocardial infarction has remained stable over the years, despite international strategies that aim to control risk factors. Two-hundredthirty cases per 100,000 are reported, with a higher impact in men, African-Americans, and those over 65 years of age. ${ }^{2}$

\section{Keywords}

Cardiovascular Diseases/complications; Coronary Thrombosis; Dissection; Young Adult; Pregnancy/ complications; Acute Coronary Syndrome; Percutaneous Coronary Intervention.
Coronary disease in adults younger than 45 years of age is always challenging. Their incidence is $0.5-2.4$ cases per 1,000 people per year and although they sometimes present classical risk factors, there are other associated conditions that must be taken into account, such as metabolic syndrome, familiar hypercholesterolemia, hypercoagulability, toxic substances (cocaine and cannabinoids), autoimmune diseases, or abnormal variants of the coronary arteries. In women, genderspecific risk factors, such as oral contraceptives, hypertensive disorders associated with pregnancy, polycystic ovarian syndrome, and menopausal-linked hypoestrogenism, increase the incidence of new events. ${ }^{3-5}$

This study reports on a case of a 44-year-old female patient with a history of a hypertensive disorder associated with pregnancy. She required temporary antihypertensive treatment, which was subsequently discontinued. Years later, she received medical care due to chest pain, documenting a coronary dissection of the marginal obtuse. Medical treatment was established with good follow-up evolution.

\section{Case report}

The patient was a 44-year-old white woman, with a history of preeclampsia 10 years ago, after which antihypertensive treatment was recommended for 6 months, with gradual suspension of medication during

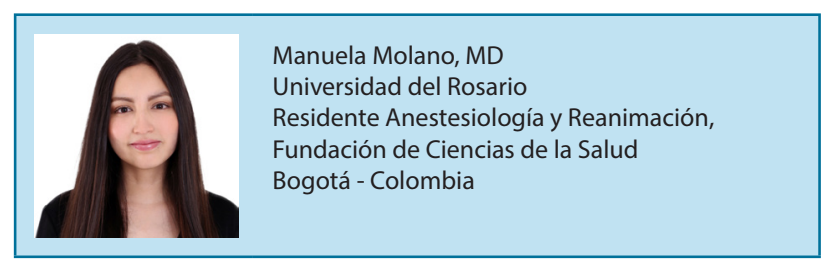

Mailing Address: Kenny Buitrago-Toro

Internal Medicine Department, Hospital Universitario Hernando Moncaleano Perdomo, Calle 9 No. 15-25. Postal Code: 410010, Neiva, Huila - Colombia E-mail: kenny9012@hotmail.com 
outpatient follow-up. She was admitted to the emergency room, reporting 48 hours of a non-irradiated oppressive chest pain, whcih intensified with effort and partially decreased at rest, associated with decreased functional class NYHA I to NYHA III. The patient was previously asymptomatic. The physical examination documented high blood pressure $170 / 90 \mathrm{mmHg}$, with no other relevant data. The electrocardiogram revealed a repolarization disorder in the upper lateral leads (Figure 1), with positive myocardial injury biomarkers (troponin I). Coronary arteriography identified a diffuse arterial narrowing, bordered by normal segments, proximal and distal to the lesion, suggestive of a type $2 \mathrm{~A}$ spontaneous dissection of the first obtuse marginal artery, with no evidence of atherothrombotic disease.

The thoracic echocardiogram revealed a left ventricle with segmental contractility disorders and mild systolic function compromise of $49 \%$, measured by Simpson. Likewise, a type I diastolic dysfunction was identified due to an alteration in relaxation.

Conservative management under antiplatelet therapy in monotherapy and a beta block was applied with satisfactory clinical evolution. At the six-month follow-up appointment, the patient had completely recovered her functional status, with improvement in left ventricular function and complete resolution of segmental contractility defect.

\section{Discussion}

Spontaneous coronary artery dissection (SCAD) is defined as the separation of the middle and the intima of a coronary epicardial artery not associated with atherosclerosis, thromboembolism, trauma, or iatrogenesis. It is an uncommon and underdiagnosed cause of acute coronary syndrome (ACS). ${ }^{5}$

Historically, the first report dates from 1931 by Pretty, who identified this condition during an autopsy of a 42-year-old woman who suffered an apparent sudden death. ${ }^{6}$ Its peak incidence is the fourth and fifth decade of life, with a predilection for the female gender in a 4:1 ratio, especially associated, although not exclusive, to the third trimester of pregnancy and postpartum. ${ }^{6,7}$

Conventional cardiovascular risk factors in this group of patients are uncommon, although the presence of hypertension (30.1\%), dyslipidemia $(20.3 \%)$, and smoking $(11.6 \%)$ have been reported. Properly for dissecting events, a high prevalence of fibromuscular dysplasia, connective diseases, autoimmune diseases, and stress situations has been reported. ${ }^{7-9}$

SCAD is the cause of $1-4 \%$ of all cases of ACS, the vast majority of which appear in women without pregnancy-related conditions. However, when analyzed in pregnant women, SCAD can reach up to $43 \%$, one of the main causes of coronary events in this population. ${ }^{6,10}$

The pathophysiological process is unclear, but a disruption of the vessel through an intimal tear that allows the creation of a false light and subsequent dissection or a hemorrhagic phenomenon of the vasa vasorum that dissects the vessel are considered. ${ }^{11}$

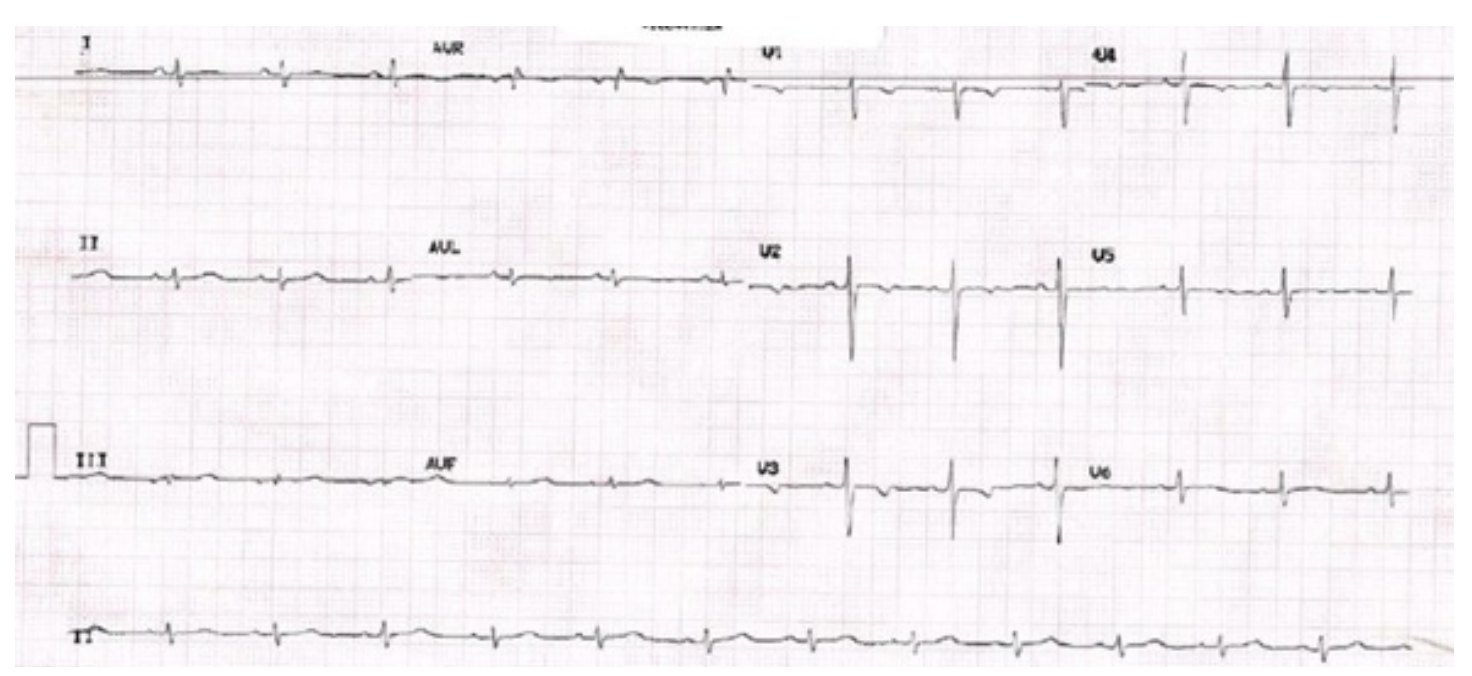

Figure 1 - EKG: sinus rhythm, repolarization disorder in the upper lateral lead 
The SCAD properly related to pregnancy can occur during the third trimester, delivery, and early or late postpartum. It is considered that estrogenic and progestogen influx could weaken the arterial walls by altering the content of elastic fibers and mucopolysaccharides, and by decreasing collagen synthesis. ${ }^{7,12}$

The clinical presentation does not vary from that of the ACS due to other causes, although the symptoms may be atypical. The Gold standard for diagnosis is coronary angiography. Intravascular ultrasound, optical coherence tomography, cardiac magnetic resonance, and coronary angiography by computed tomography are also considered highly sensitive and specific. $5,6,13$

Medical conservative management is preferred in hemodynamically stable patients since the affected artery heals spontaneously. Invasive procedures may precipitate, or extend the dissection and even a rupture. Interventional management is indicated for those patients with left main trunk involvement or proximal dissections of more than two vessels associated with hemodynamic instability or refractory angina. Thrombolytic therapy should be avoided. ${ }^{7-9}$

Medical treatment is based on dual anti-aggregation (monotherapy has been reported in low risk patients) for a minimum of 6 months, with a beta blocker (especially if there is left ventricular dysfunction or arrhythmia control) and a strict control of comorbidities. Severe acute stressful situations should be avoided, and Valsalva maneuver activities should be performed. Statins, since there is no atherosclerotic disease, are not recommended ${ }^{7,10}$

Prognosis is usually good. Intrahospital major adverse events were documented in $8.8 \%$, rising to $22 \%$ in peripartum. The majority of patients achieve vessel remodeling and spontaneous healing on day 30 in follow-up angiographies, and recurrence is around $10 \%{ }^{10-13}$

In patients who report fibromuscular dysplasia, especially at the renal level with associated renal ischemic disease, stent angioplasty, or renal revascularization, should be considered in order to avoid acute hypertensive crises mediated by renal hypoperfusion. ${ }^{14}$

\section{Conclusion}

Coronary dissection is a cause to bear in mind in young women patients with acute coronary syndrome, with or without ST segment elevation, with no associated cardiovascular risk factors. The diagnosis is based on arteriography and is part of the spectrum in cases of MINOCA (myocardial infarction with healthy coronaries). Medical management is essential and actively seeks the underlying cause to prevent recurrences.

\section{Author contributions}

Conception and design of the research: Mora MA, Molano-Perez M, Becerra-Gonzalez CO, Buitrago-Toro $\mathrm{K}$, Jimenez-Salazar S, Ortiz C. Acquisition of data: Mora MA, Molano-Perez M, Becerra-Gonzalez CO, BuitragoToro K, Jimenez-Salazar S, Ortiz C. Analysis and interpretation of the data: Mora MA, Molano-Perez M, Becerra-Gonzalez CO, Buitrago-Toro K, Jimenez-Salazar S, Ortiz C. Statistical analysis: Mora MA, Molano-Perez M, Becerra-Gonzalez CO, Buitrago-Toro K, JimenezSalazar S, Ortiz C. Writing of the manuscript: Mora MA, Molano-Perez M, Becerra-Gonzalez CO, BuitragoToro K, Jimenez-Salazar S, Ortiz C. Critical revision of the manuscript for intellectual content: Mora MA, Molano-Perez M, Becerra-Gonzalez CO, Buitrago-Toro K, Jimenez-Salazar S, Ortiz C.

\section{Potential Conflict of Interest}

No potential conflict of interest relevant to this article was reported.

\section{Sources of Funding}

There were no external funding sources for this study.

\section{Study Association}

This study is not associated with any thesis or dissertation work.

\section{Ethics approval and consent to participate}

This article does not contain any studies with human participants or animals performed by any of the authors. 


\section{References}

1. Benjamin EJ, Muntner P, Bittencourt MS. Heart disease and stroke statistics-2019 update: a report from the American Heart Association. Circulation. 2019;139(10):e56-e528.

2. Sanchis-Gomar F, Perez-Quilis C, Leischik R, Lucia A. Epidemiology of coronary heart disease and acute coronary syndrome. Ann Transl Med.2016;4(13):256.

3. Andersson C, Vasan RS. Epidemiology of cardiovascular disease in young individuals. Nat Rev Cardiol. 2018;15(4):230-40.

4. Mehta PK, Wei J, Wenger NK. Ischemic heart disease in women: a focus on risk factors. Trends Cardiovasc Med. 2015;25(2):140-51.

5. Filali T, Lahidheb D, Gommidh M, Jdaida B, Hajlaoui N, Fehri W, et al. Spontaneous multivessel coronary artery dissection associated with cannabis use. Journal of cardiology cases. 2013;7(1):e4-e7.

6. Pretty HC. Dissecting aneurysm of coronary artery in a woman aged 42 : rupture. Brit Med J. 1931;1:667.

7. Hayes SN, Kim ES, Saw J, Adlam D, Arslanian-Engoren C, Economy KE, et al. Spontaneous coronary artery dissection: current state of the science: a scientific statement from the American Heart Association. Circulation. 2018;137(19):e523-e57.

8. Almaddah NK, Morsy MS, Dishmon D, Khouzam RN. Spontaneous coronary artery dissection: An often unrecognized cause of acute coronary syndrome. Clev Clin J Med. 2019;86(4):252-6.
9. Muñoz C, Perelli J, Robert S, Lindefjeld D, Zalaquett R. Disección coronaria espontánea: comunicación de 2 casos tratados quirúrgicamente. Rev Med Chile. 2016;144(2):257-61.

10. Gilhofer TS, Saw J. Spontaneous coronary artery dissection: a review of complications and management strategies. Expert review of cardiovascular therapy. Curr Opin Cardiol.2019;17(4):275-91.

11. Saw J, Starovoytov A, Humphries K, Sheth T, So D, Minhas K, et al. Canadian spontaneous coronary artery dissection cohort study: inhospital and 30-day outcomes. Eur Heart J. 2019;40(15):1188-97.

12. Hassan S, Prakash R, Starovoytov A, Saw J. Natural history of spontaneous coronary artery dissection with spontaneous angiographic healing. JACC: Cardiovascular Interventions. 2019;12(6):518-27.

13. Saw J, Humphries K, Aymong E, Sedlak T, Prakash R, Starovoytov A, et al. Spontaneous coronary artery dissection: clinical outcomes and risk of recurrence. Journal of the American College of Cardiology. 2017;70(9):1148-58.

14. Narula N, Kadian-Dodov D, Olin JW. Fibromuscular dysplasia: contemporary concepts and future directions. Progress in cardiovascular diseases. 2018;60(6):580-5. 